\title{
Stability of inorganic arsenic species in simulated raw waters with the presence of NOM
}

\author{
G.J. Liu*, X.R. Zhang ${ }^{\star *}$, J. Jain ${ }^{\star \star \star}$, J.W. Talley ${ }^{\star \star * *}$ and C.R. Neal* \\ *Department of Civil Engineering and Geological Sciences, University of Notre Dame, Notre Dame, IN \\ 46556, USA (E-mail: gliu@nd.edu; neal.1@nd.edu) \\ **Department of Civil Engineering, Hong Kong University of Science and Technology, Hong Kong, China \\ (E-mail: xiangru@ust.hk) \\ ***Hanford Tank Waste Treatment Plant, 2435 Stevens Center PI, MS12-B, Richland, WA 99354, USA \\ (E-mail: jcjain@bechtel.com)
}

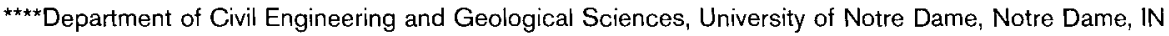
46556, USA (E-mail: jtalley1@nd.edu)

\begin{abstract}
Effect of natural organic matter (NOM) on the stability of inorganic arsenic species in simulated raw water was examined at circumneutral $\mathrm{pH}$. An ion chromatography-inductively coupled plasma mass spectrometry system was used for simultaneous determination of $A s(I I)$ and $A s(V)$. A reduction of arsenate $(\mathrm{As}(\mathrm{V})$ ) to arsenite $(\mathrm{As}(\mathrm{III})$ ) was observed in the unfiltered simulated raw waters (USW). The As(V) reduction to As(III) did not occur in the simulated waters that passed through a $0.2 \mu \mathrm{m}$ membrane (FSW). Microorganism activities is probably the major reason causing As(V) reduction in the USW. In the FSW without NOM, As(III) tended to be oxidized into $\mathrm{As}(\mathrm{V})$. The addition of $0.036 \mathrm{mM}$ of Fe(II) significantly facilitated the oxidation. The presence of $10 \mathrm{mg} / \mathrm{L}$ Suwannee River NOM as C inhibited As(III) oxidation no matter whether Fe(II) existed or not. The experimental results suggest that NOM can mediate distribution of inorganic arsenic species in water, thus it is an important factor controlling the mobility and toxicity of arsenic in drinking water.
\end{abstract}

Keywords As(III); As(V); Fe(II); NOM; oxidation

\section{Introduction}

Arsenic is a human carcinogen that attacks multiple sites in the human body (Smith et al., 2000; LaGrega et al., 2001). In order to reduce the potential risks that arsenic may cause to human health, the World Health Organization recommended a maximum arsenic concentration in drinking water as $10 \mu \mathrm{g} / \mathrm{L}$ (WHO, 1993). In 2001, the U.S. Environmental Protection Agency adopted the $10 \mu \mathrm{g} / \mathrm{L}$ standard for arsenic in drinking water, replacing the old standard of $50 \mu \mathrm{g} / \mathrm{L}$ (USEPA, 2001). Based upon the latest data and statistics, it is estimated that around 40 million people in Bandladesh are at risk of chronic arsenic poisoning (Karim, 2000). Arsenic in source drinking water originates naturally from the weathering arsenic-containing rocks and soils. It exists in water primarily as oxyanions of trivalent arsenite, (As(III)), or pentavalent arsenate, (As(V)) (Smedley, et al., 2002). As a contaminant in water, As(III) is more problematic than As(V) since As(III) is more toxic and more mobile than As(V) (Viraraghaven et al., 1999). Because of the variation in toxicity and removal efficiency between As(III) and As(V) (Jiang, 2001), knowledge on the speciation distribution in drinking water is essential.

The inorganic arsenic species are unstable in natural waters due to the transformation between $\mathrm{As}(\mathrm{III})$ and $\mathrm{As}(\mathrm{V})$. The stability of $\mathrm{As}(\mathrm{III})$ and $\mathrm{As}(\mathrm{V})$ in aquatic environment has been reported to be dependent on water $\mathrm{pH}$, redox potential, the presence of microbes, and the presence of precipitating metals such as $\mathrm{Mn}$ and Fe (Spliethoff et al., 
1995; Smedley et al., 2002). In oxic waters, As(III) tends to be oxidized into As(V), while in anoxic and acidic waters, As(V) tends to be reduced to As(III) (Smedley et al., 2002). The redox reactions between $A s(I I I)$ and $A s(V)$ can be facilitated or inhibited by the presence of microbes or metals in water (McCleskey, 2004). For example, $500 \mu \mathrm{g} / \mathrm{L}$ of As(III) in a simulated groundwater was found to be almost completely oxidized into $\mathrm{As}(\mathrm{V})$ within $100 \mathrm{~min}$ at $\mathrm{pH} 7.8-8.0$ with several additions of $2 \mathrm{mg} / \mathrm{L} \mathrm{Fe}$ (II), whereas the same amount of As(III) in the same simulated water could keep its redox speciation for weeks if Fe(II) was not added (Hug et al., 2001). Though extensive studies have been conducted on the stability of arsenic in various water samples, accurate determination of arsenic redox speciation in a specific natural water remains difficult as many other factors that may affect arsenic stability have not been considered in previous studies. For instance, little information is available on how natural organic matter (NOM) affects the stability of $\mathrm{As}(\mathrm{III})$ and $\mathrm{As}(\mathrm{V})$ in water.

NOM is a complex mixture of acidic organic molecules that originates from a variety of natural sources. It is ubiquitous in natural waters and is an essential element controlling the fate and bioavailability of heavy metals in aquatic environment. NOM possesses unique combinations of functional groups, including carboxylic, esteric, phenolic, quinone, amino, nitroso, sulfhydryl, hydroxyl, and other moieties. The hydroquinone moieties within NOM are redox active and may react with inorganic arsenic species or compete with them for oxidants or reductants, and thus thermodynamically or kinetically affect the distribution of As(III) and As(V) in natural waters. Redman et al. (2002) and Ko et al. (2004) reported that NOM affected inorganic arsenic speciation distribution in synthetic raw water at $\mathrm{pH} 6.0-7.0$ after 2-4 day incubation. The effect of NOM on arsenic transformation kinetics was not discussed in their papers.

The primary objective of this study was to investigate the effect of NOM on the stability of inorganic arsenic species in simulated raw waters. An ion chromatography-inductively coupled plasma mass spectrometry (IC-ICP-MS) system was used to simultaneously determine the concentrations of As(III) and As(V) in water. The effect of NOM on the Fe(II) catalytic oxidation of As(III) was also examined.

\section{Experimental methods}

\section{Materials}

All chemicals were of analytical grade. Milli-Q water was supplied by the Millipore MR3 water purifier system. Suwannee River NOM (SRNOM), a well characterized NOM, was purchased from the International Humic Substances Society. Sodium arsenite $\left(\mathrm{NaAsO}_{2}, 99 \%\right)$ and sodium arsenate $\left(\mathrm{Na}_{2} \mathrm{HAsO}_{4} \cdot 7 \mathrm{H}_{2} \mathrm{O}, 99 \%\right)$ were obtained from Sigma-Aldrich. Sodium chloride $(\mathrm{NaCl}, 98 \%)$ and ferrous sulfate $\left(\mathrm{FeSO}_{4} \cdot 7 \mathrm{H}_{2} \mathrm{O},>99 \%\right)$ were purchased from Fisher.

The stock solution of $\mathrm{As}(\mathrm{III})$ or $\mathrm{As}(\mathrm{V})(13.3 \mathrm{mM})$ was prepared by dissolving a given amount of $\mathrm{NaAsO}_{2}$ or $\mathrm{Na}_{2} \mathrm{HAsO}_{4} \cdot 7 \mathrm{H}_{2} \mathrm{O}$ in Milli-Q water. The arsenic stock solutions were stored in high density polyethylene bottles, and were kept in a refrigerator at $4^{\circ} \mathrm{C}$ for up to 6 weeks. The simulated raw water without NOM was prepared by dissolving $0.585 \mathrm{~g} \mathrm{NaCl}$ in $1 \mathrm{~L}$ Milli-Q water. The simulated raw waters with NOM was prepared by mixing $20 \mathrm{~mL}$ SRNOM stock solution $(500 \mathrm{mg} / \mathrm{L}$ as C) with $980 \mathrm{~mL}$ simulated water without NOM in order to reach a NOM concentration of $10 \mathrm{mg} / \mathrm{L}$ as $\mathrm{C}$. The $\mathrm{pH}$ values of the simulated waters were adjusted to $6.0 \pm 0.1$. Some aliquots of the simulated raw waters were filtered through a $0.2 \mu \mathrm{m}$ membrane (Gelman FP-Verical) to remove microbes. The unfiltered simulated raw water and filtered simulated raw water are denoted as USW and FSW, respectively. 


\section{Experimental procedures}

Batch experiments were performed to investigate the stability of arsenic species in simulated raw waters with and without NOM. The stock As(III) and As(V) solutions were diluted with $10 \mathrm{~mL}$ simulated raw waters with/without NOM, and were mixed to produce a total arsenic level of $0.4-1 \mu \mathrm{M}$. The $\mathrm{pH}$ of the mixture was adjusted to $6.0 \pm 0.1$ using diluted $0.1 \mathrm{M} \mathrm{HCl}$ or $0.1 \mathrm{M} \mathrm{NaOH}$. The solutions were then sealed and shaken gently at $100 \mathrm{rpm}$ in the dark to avoid photooxidation. All experiments were performed at room temperature $\left(22^{\circ} \mathrm{C}\right)$. Samples were taken at 0.5 , $1,2,4,7 \mathrm{~d}$, and were stored in the dark at $4^{\circ} \mathrm{C}$ till analysis.

To study the effect of NOM on As(III) stability with the presence of Fe(II), the simulated raw waters were mixed with a concentrated Fe(II) solution to prepare solutions containing $0.036 \mathrm{mM} \mathrm{Fe}(\mathrm{II})(2 \mathrm{mg} / \mathrm{L}$ as $\mathrm{Fe}$ ) right before the addition of $\mathrm{As}$ (III). To preserve the arsenic speciation, $50 \mu \mathrm{L}$ of $2 \mathrm{M} \mathrm{H}_{2} \mathrm{SO}_{4}$ was added into $10 \mathrm{~mL}$ of the solutions to lower the $\mathrm{pH}$ to less than 2.0 .

\section{Arsenic analysis}

The concentrations of the two inorganic arsenic species were determined simultaneously using an IC-ICP-MS system. Both As(III) and As(V) behave like weak acids in water. The dissociation constants for As(III) and As(V) are 9.29 (Korte and Fernando, 1991) and 2.26 (Perrin, 1982) respectively. Within the pH range of 3.0 to 9.0 , As(III) exists primarily as uncharged $\mathrm{H}_{3} \mathrm{AsO}_{3}^{0}$, whereas the predominant species for $\mathrm{As}(\mathrm{V})$ include monovalent $\mathrm{H}_{2} \mathrm{AsO}_{4}^{-}$and divalent $\mathrm{HAsO}_{4}^{2-}$. Therefore, As(III) and $\mathrm{As}(\mathrm{V})$ can be separated with an anion exchange column. In this study, a Dionex AS7 column with an AG7 guard column was used to separate $\mathrm{As}(\mathrm{III})$ and $\mathrm{As}(\mathrm{V})$ in the simulated raw waters. The mobile phases used were $0.5 \mathrm{mM}$ $\mathrm{HNO}_{3}$ and $50 \mathrm{mM} \mathrm{HNO}$. The pHs of the two mobile phases were $3.3 \pm 0.1$ and $1.8 \pm 0.1$, respectively. The detailed gradient programme for separating As(III) and As(V) was based on Kohlmeyer et al. (2002) and is present in Table 1. An on-line AD25 UV detector was used to monitor the amount of NOM in the sample. The concentrations of the separated arsenic species were detected using a Finnigan Element 2 sector field high resolution ICP-MS (Thermo Electron Corporation). The ICP-MS has a quartz concentric nebulizer and a quartz double pass spray chamber. The sampling and skimmer cones were made of Nickel. The peak areas of different arsenic species in standards and samples were obtained by integrating the ICP-MS signal with time using the software of Matlab 6.5. The detection limit for As(III) or $\mathrm{As}(\mathrm{V})$ was $0.2 \mu \mathrm{g} / \mathrm{L}$, which is equivalent to $0.0026 \mu \mathrm{M}$ of arsenic. The relative standard deviations for three injections of a sample were within $2 \%$. The retention time shifts for $\mathrm{As}(\mathrm{III})$ and $\mathrm{As}(\mathrm{V})$ were less than $1.7 \%$.

Table 1 Gradient programme for $A s(I I)$ and $A s(V)$ separation using the Dionex AS7 column with a AG7 guard column

\begin{tabular}{|c|c|c|c|}
\hline Time (min) & Phase A (0.5 mM HNO 3 , pH 3.3) & Phase B (50 mM HNO 3, pH 1.8) & Pump mode \\
\hline $0-3.0$ & $100 \%$ & 0 & Isocratic \\
\hline $3.0-4.0$ & $50 \%$ & $50 \%$ & Linear \\
\hline $4.0-9.0$ & $50 \%$ & $50 \%$ & Isocratic \\
\hline $9.0-10.0$ & $100 \%$ & 0 & Linear \\
\hline $10.0-15.0$ & $100 \%$ & 0 & Isocratic \\
\hline
\end{tabular}




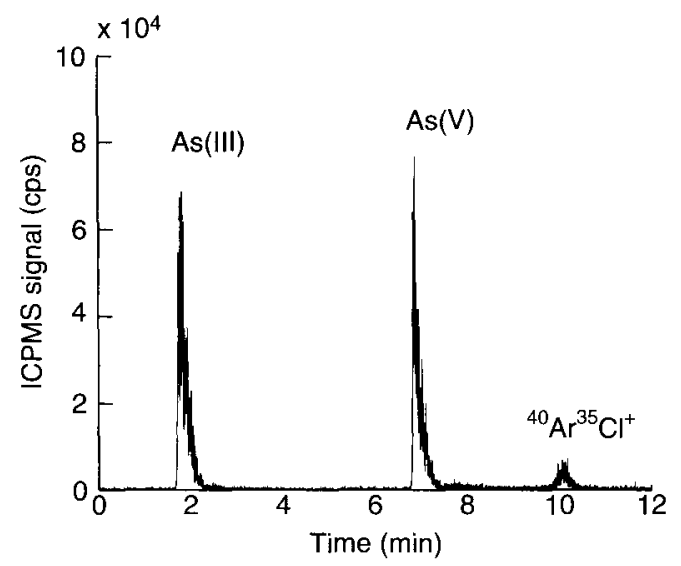

Figure 1 Anion-exchange chromatogram showing the separation of $\mathrm{As}(\mathrm{III})$ and $\mathrm{As}(\mathrm{V})$

\section{Results and discussion}

\section{IC-ICP-MS chromatograms for As(III) and As(V)}

Figure 1 presents a typical chromatogram, for the conditions listed in Table 1, of a sample containing As(III) and As(V). The sample contained $0.27 \mu \mathrm{M}(20 \mu \mathrm{g} / \mathrm{L})$ of each arsenic species and $10 \mathrm{mM} \mathrm{NaCl}$. The chromatogram shows that $\mathrm{As}(\mathrm{III})$ and $\mathrm{As}(\mathrm{V})$ could be completely separated within $8 \mathrm{~min}$. The retention times for $\mathrm{As}(\mathrm{III})$ and $\mathrm{As}(\mathrm{V})$ were 1.8 and 6.9 min, respectively. Besides the peaks of $\mathrm{As}(\mathrm{III})$ and $\mathrm{As}(\mathrm{V})$, there was an additional peak eluted at $10 \mathrm{~min}$. The peak area of the additional peak did not change with the As(III) or As(V) concentration, but it increased significantly as the $\mathrm{Cl}^{-}$concentration in the sample was increased from $10 \mathrm{mM}$ to $100 \mathrm{mM}$. This observation suggests that the additional peak in the chromatogram was caused by ${ }^{40} \mathrm{Ar}^{35} \mathrm{Cl}^{+}$dimer, which is consistent with the literature (Kohlmeyer et al, 2002). The addition of $10-50 \mathrm{mg} / \mathrm{L}$ SRNOM as C in the sample neither changed the retention times of the two arsenic species nor produced any other peaks in the chromatogram. No peaks were observed from the on-line AD25 UV detector during the period of analysis, which suggests that SRNOM or its complex with arsenic was retained in the anion exchange column during the separation process.

\section{Arsenic stability in USW or FSW without NOM}

The stability of the inorganic arsenic redox species in USW or FSW was examined and the results are presented in Figure 2. The initial total arsenic concentration was $\mathbf{I} M \mathbf{M}$, with an initial $\mathrm{As}(\mathrm{III}) / \mathrm{As}(\mathrm{V})$ ratio of $1: 1$. NOM was not present in these simulated waters.
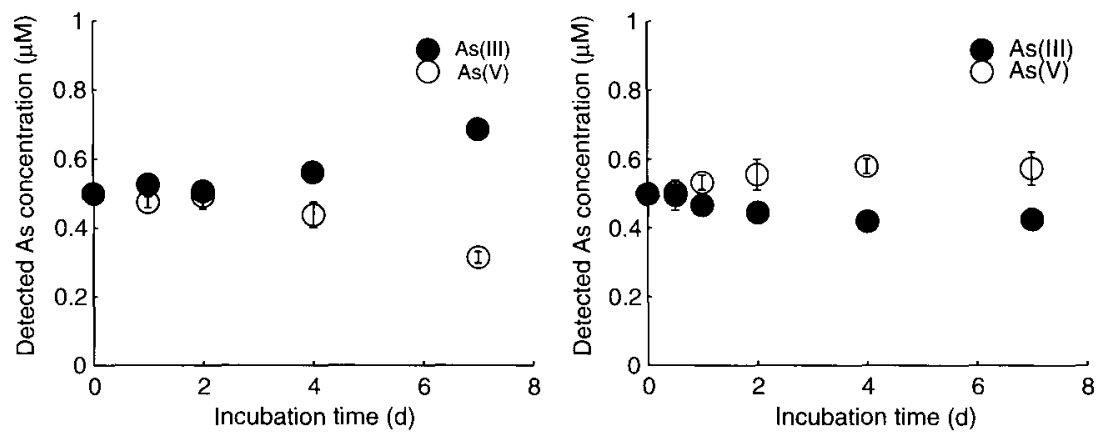

Figure 2 Stability of $A s(I I I)$ and $A s(V)$ in (a) USW and (b) FSW. Error bar represents the relative error for duplicate samples. Total arsenic concentration, $1 \mu \mathrm{M}$; Initial As(III)/As(V) ratio, $1: 1 ; \mathrm{pH}, 6.0$ 
Figure 2(a) shows the concentration change of $\mathrm{As}(\mathrm{III})$ and $\mathrm{As}(\mathrm{V})$ in the USW with time. The concentration of As(III) increased gradually in USW. The increase of As(III) was in accompany with the decrease of $\mathrm{As}(\mathrm{V})$. The sum concentration of the two arsenic species remained unchanged within $7 \mathrm{~d}$, suggesting that $\mathrm{As}(\mathrm{V})$ was gradually reduced to As(III). The standard reduction potentials of $\mathrm{As}(\mathrm{V}) / \mathrm{As}(\mathrm{III})$ couple for various species in water are listed in Equations 1-4 (Santhanam and Sundaresan, 1985). The standard reduction potential for $\mathrm{O}_{2} / \mathrm{H}_{2} \mathrm{O}$ is expressed in Equation 5 (Lide et al., 2004). Under the experimental conditions, the major species of $\mathrm{As}(\mathrm{III})$ and $\mathrm{As}(\mathrm{V})$ species are $\mathrm{H}_{3} \mathrm{AsO}_{3}$ (equivalent to $\mathrm{HAsO}_{2}$ ) and $\mathrm{H}_{2} \mathrm{AsO}_{4}^{-}$, respectively. The $\mathrm{E}^{\mathrm{O}}(\mathrm{As}(\mathrm{V}) / \mathrm{As}(\mathrm{III})$ ) at $\mathrm{pH} 6.0$ can be obtained from the Nernstian Equation 2, which is $0.139 \mathrm{~V}$. Since the initial ratio of $\mathrm{As}(\mathrm{V})$ to $\mathrm{As}(\mathrm{III})$ was $1: 1$, the redox potential of $\mathrm{As}(\mathrm{V}) / \mathrm{As}(\mathrm{III})$ should be $0.139 \mathrm{~V}$ under the experimental conditions. According to Eq.5, the standard potential of $\mathrm{O}_{2} / \mathrm{H}_{2} \mathrm{O}$ is $(1.229-0.059 \mathrm{pH})$, which equals to $0.875 \mathrm{~V}$ at $\mathrm{pH} \mathrm{6.0}$. Considering the concentration of dissolved oxygen, which was found to vary from $4.7-3.3 \mathrm{mg} / \mathrm{L}$ in the simulated waters, the redox potential of $\mathrm{O}_{2} / \mathrm{H}_{2} \mathrm{O}$ should be within the range of $0.818-0.816 \mathrm{~V}$, which is more positive than that of $\mathrm{As}(\mathrm{V}) / \mathrm{As}(\mathrm{III})$. The thermodynamic calculation indicates that the reduction of $\mathrm{As}(\mathrm{V})$ to $\mathrm{As}(\mathrm{III})$ would be unlikely unless some reducing agents existed in the USW.

$$
\begin{array}{cl}
\mathrm{H}_{3} \mathrm{AsO}_{4}+2 \mathrm{H}^{+}+2 \mathrm{e}^{-}=\mathrm{HAsO}_{2}+2 \mathrm{H}_{2} \mathrm{O} & E^{0}=0.56 \mathrm{~V} \\
\mathrm{H}_{2} \mathrm{AsO}_{4}^{-}+3 \mathrm{H}^{+}+2 \mathrm{e}^{-}=\mathrm{HAsO}_{2}+2 \mathrm{H}_{2} \mathrm{O} & E^{0}=0.67 \mathrm{~V} \\
\mathrm{HAsO}_{4}^{2-}+4 \mathrm{H}^{+}+2 \mathrm{e}^{-}=\mathrm{HAsO}+2 \mathrm{H}_{2} \mathrm{O} & E^{0}=0.88 \mathrm{~V} \\
\mathrm{AsO}_{4}^{3-}+2 \mathrm{H}_{2} \mathrm{O}+2 \mathrm{e}^{-}=\mathrm{AsO}_{2}^{-}+4 \mathrm{OH}^{-} & E^{0}=-0.67 \mathrm{~V} \\
1 / 2 \mathrm{O}_{2}+2 \mathrm{H}^{+}+2 \mathrm{e}^{-}=2 \mathrm{H}_{2} \mathrm{O} & E^{0}=-1.229 \mathrm{~V}
\end{array}
$$

The stability of As(III) and As(V) in FSW is presented in Figure 2(b). Contrary to the result obtained in the USW, As(III) tended to be oxidized to As(V) in the FSW instead of the reduction of As(V) to As(III) (Figure 2(a)). The gradual oxidation of As(III) to As(V) is not surprising according to the aforementioned thermodynamic calculation. The dissolved $\mathrm{O}_{2}$ in the simulated waters should be responsible for the oxidation of As(III) to $\mathrm{As}(\mathrm{V})$ in FSW.

The comparison of Figures 2(a) and 2(b) suggests that the reducing agents existing in the USW could not pass through the $0.2-\mu \mathrm{m}$ membrane. The reduction of $\mathrm{As}(\mathrm{V})$ to As(III) in deionized water was also reported in Hall et al. (1999), in which microorganism activities were considered to be the major reason for the $A s(V)$ reduction. Our results appear to support this hypothesis because almost all the microbes in water can be removed by a $0.2 \mu \mathrm{m}$ membrane. Another explanation for the observed As(V) reduction in the USW could be the presence of granular activated carbon (GAC), which is used in in the Millipore water purifier system for removing organic impurities. Accordingly, the effect of GAC on As(V) stability in the FSW was examined. No As(III) was detected after the solution of $1 \mu \mathrm{M}$ As(V) was mixed with $2 \mathrm{mg} / \mathrm{L}$ of GAC for $7 \mathrm{~d}$ (data not shown). The total concentration of arsenic in solution, however, decreased significantly with the presence of GAC, suggesting that the GAC could adsorb arsenic in the solution. The result suggests that GAC might not be the major reason for the reduction of $A s(V)$ to As(III) in the USW. Further experiments regarding the adsorption capability of GAC to As(III) is needed to confirm this. 
The stability of the two inorganic arsenic species in the presence of $10 \mathrm{mg} / \mathrm{L} \mathrm{SRNOM}$ as $\mathrm{C}$ was examined. To avoid the interference from microbes and/or other possible reducing agents in the Milli-Q water, the FSW was used in all experiments. The results are presented in Figure 3.

With the presence of $10 \mathrm{mg} / \mathrm{L}$ SRNOM as C, the concentrations of As(III), As(V), and total arsenic in the simulated raw waters did not change within $7 \mathbf{d}$, which is different from the results obtained in FSW without NOM (Figure 2(b)). The comparison of Figures 4 with Figure 2(b) suggests that SRNOM tended to inhibit As(III) oxidation.

NOM possesses unique combinations of functional groups, including carboxylic, esteric, phenolic, quinone, amino, nitroso, sulfhydryl, hydroxyl, and other moieties. The hydroquinone moieties within NOM are redox active and may react with $\mathrm{As}(\mathrm{V})$ or $\mathrm{O}_{2}$, and thus thermodynamically or kinetically inhibited the oxidation of As(III) to As(V) in the simulated raw waters. Since the oxidation of $\mathrm{As}(\mathrm{III})$ to $\mathrm{As}(\mathrm{V})$ without NOM was mainly due to dissolved oxygen in water, the inhibited As(III) oxidation in the presence of NOM indicates that NOM seems to undergo oxidized degradation under our experimental conditions.

\section{As(III) stability in presence of NOM and Fe(II)}

$\mathrm{Fe}$ (II) is a common component in natural waters. It is also an essential element controlling the speciation transformation between $A s(I I I)$ and $A s(V)$ in aquatic environment. Upon exposure to air or oxygen, the presence of Fe(II) can significantly accelerate the oxidation of As(III) to As(V) (Hug et al., 2001; Samanta and Clifford, 2005). Among the limited publications regarding Fe(II) facilitated oxidation of As(III), few of them have shown the role of NOM during this process. Accordingly, the stability of As(III) in the presence of $\mathrm{Fe}$ (II) with and without NOM was examined, and the results are presented in Figure 4. The FSW was used in these experiments.

Figure 4(a) shows As(III) stability with and without Fe(II) in the FSW that did not contain NOM. No matter whether Fe(II) was present in the simulated waters or not, the concentration of As(III) decreased with time. In the absence of Fe(II), As(V) concentration increased with time, and the total concentration of the two arsenic species did not change. It suggests that As(III) was transformed to As(V). After 4d, about 14\% of As(III) was oxidized into As(V) in the FSW. In the presence of $\mathrm{Fe}(\mathrm{II}), \mathrm{As}(\mathrm{V})$ concentration initially increased with time and then decreased after $2 \mathrm{~d}$. About $0.1 \mu \mathrm{M}$ of As(V)

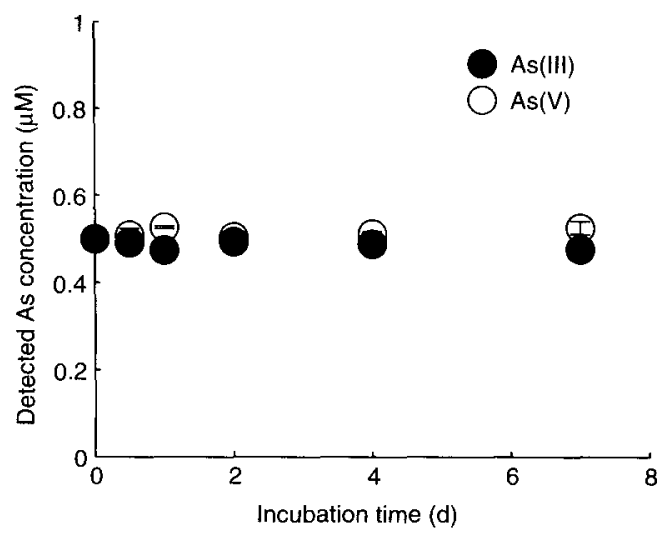

Figure 3 Stability of $A s(I I)$ and $A s(V)$ in FSW with the presence of SRNOM. Error bar represents the relative error for duplicate samples. Initial arsenic concentration, $1 \mu \mathrm{M}$; Initial $\mathrm{As}(\mathrm{III}) / \mathrm{As}(\mathrm{V})$ ratio, $1: 1$; Initial 

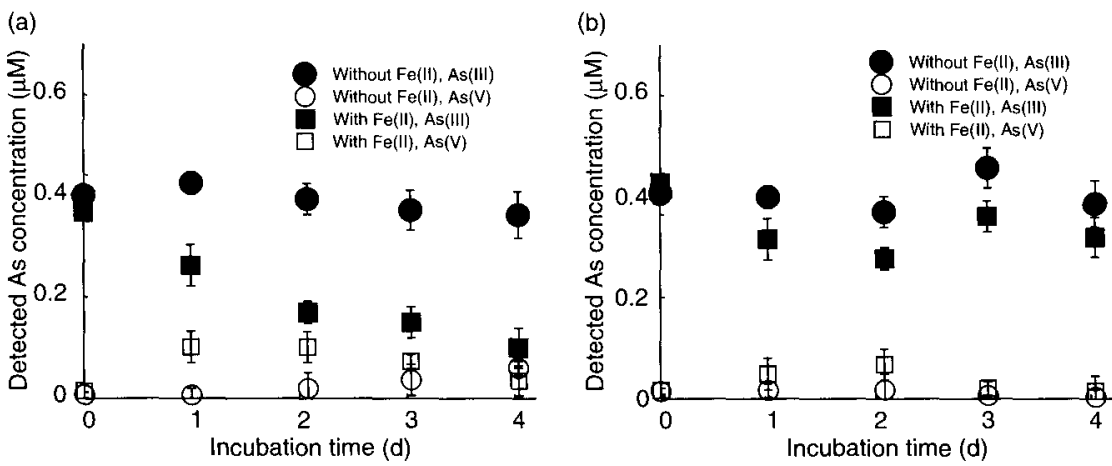

Figure 4 Effect of Fe(II) on As(III) stability in FSW (a) without and (b) with the presence of SRNOM. Error bar represents the relative error for duplicate samples. Initial As(III) concentration, $0.4 \mu \mathrm{M}$; Initial NOM concentration, $10 \mathrm{mg} / \mathrm{L}$ as $\mathrm{C} ; \mathrm{pH}, 6.0$

was detected in the FSW by the end of the 2-d incubation. The detected As(V) was equivalent to $25 \%$ of the initial amount of As. The results suggest that $\mathrm{Fe}$ (II) facilitated the oxidation of As(III) in the FSW. The catalytic effects of Fe(II) on As(III) oxidation in natural waters have been reported in the literature (Hug et al., 2001). Figure 4(a) also suggests that the total concentration of $\mathrm{As}(\mathrm{III})$ and $\mathrm{As}(\mathrm{V})$ decreased gradually in the NOM-free FSW that contained Fe(II). A similar phenomenon was also observed by Samanta and Clifford (2005). They ascribed the mass loss of the total inorganic arsenic in solution to the adsorption of $\mathrm{As}(\mathrm{V})$ onto iron hydroxide, which was formed when $\mathrm{Fe}$ (II) was oxidized into $\mathrm{Fe}$ (III). In our experiments, all the samples were acidified to $\mathrm{pH}<2.0$ using $2 \mathrm{M} \mathrm{H}_{2} \mathrm{SO}_{4}$. The formed iron hydroxide would be dissolved under such an acidic condition, and the As(V) attached to the iron hydroxide surface would be re-dissolved into the solution. It seems unlikely that the gradual loss of arsenic was caused by the adsorption of $\mathrm{As}(\mathrm{V})$ by iron hydroxide. One possible explanation for the observed mass loss of As(V) and the total inorganic arsenic (As(III) + As(V)) after the 2-d incubation is that $\mathrm{As}(\mathrm{V})$ and Fe(III) reacted to formed new compounds that has very low solubility even at low $\mathrm{pH}$ values. The new compounds could be crystalline sorodite $\left(\mathrm{FeAsO} \mathrm{A}_{4} \cdot 2 \mathrm{H}_{2} \mathrm{O}\right)$ and/or amorphous $\mathrm{FeAsO}_{4} \cdot \mathrm{xH}_{2} \mathrm{O}$.

Figure 4(b) shows As(III) stability with and without Fe(II) in the FSW that contained $10 \mathrm{mg} / \mathrm{L}$ SRNOM as C. In the absence of Fe(II), almost no As(III) was oxidized into As(V) after $4 \mathrm{~d}$. The addition of $0.036 \mathrm{mM}$ of Fe(II) slightly accelerate As(III) oxidation. When $\mathrm{Fe}$ (II) was present in the simulated waters, the concentration of As(V) initially increased with time and then decreased after the 2-d incubation. The trend for the change of As(V) concentration with time is similar with that obtained in the NOM-free FSW (Figure 4(a)). Maximum As(V) concentration detected in the FSW that contain NOM and Fe(II) was $0.068 \mu \mathrm{M}$, which is equivalent to $17 \%$ of the initial As concentration. The experimental results suggest that the catalytic effect of $\mathrm{Fe}(\mathrm{II})$ on $\mathrm{As}$ (III) oxidation was smaller in the presence NOM compared to that in the absence of NOM. NOM has strong complexation capability with various types of metals. The complexation between NOM and Fe(II) may inhibit $\mathrm{Fe}$ (II) oxidation to $\mathrm{Fe}$ (III) and therefore inhibit the oxidation of $\mathrm{As}(\mathrm{III})$ to $\mathrm{As}(\mathrm{V})$.

\section{Acknowledgements}

This research was funded by the National Science Foundation (NSF EAR02-21966) through the Environmental Molecular Scientific Institute at the University of Notre Dame. We thank John Shafer, Jennifer Szmanowski, and William Kinman for their help in laboratory analysis and instrument maintenance. 


\section{References}

Hall, G.E.M., Pelchat, J.C. and Gauthier, G. (1999). Stability of inorganic arsenic(III) and arsenic(V) in water samples. J. Anal. At. Spectrom., 14, 205-213.

Hug, S.J., Canonica, L., Wegelin, M., Gechter, D. and Gunten, U.V. (2001). Solar oxidation and removal of arsenic at circumneutral pH in iron containing waters. Environ. Sci. Technol, 35, 2114-2121.

Jiang, J.Q. (2001). Removing arsenic from groundwater for the developing world-a review. Wat. Sci. Technol., 44(6), 89-98.

Karim, M. (2000). Arsenic in groundwater and health problems in Bangladesh. Wat. Res., 34, 304-310.

Ko, I., Kim, J.-Y. and Kim, K.-W. (2004). Arsenic speciation and sorption kinetics in the As-hematite-humic acid system. Colloids Surf., A: Physicochem. Eng. Aspects, 234, 43-50.

Kohlmeyer, U., Kuballa, J. and Jantzen, E. (2002). Simultaneous separation of 17 inorganic and organic arsenic compounds in marine biota by means of high-performance liquid chromatograph/inductively coupled plasma mass spectrometry. Rapid Commun. Mass Spectrom., 16, 965-974.

Korte, N.E. and Fernando, Q. (1991). A review of As(III) in groundwater. Crit. Rev. Environ. Control., 21(1), $1-39$.

LaGrega, M.D., Buckingham, P.L. and Evans, J.C. (2001). Hazardous Waste Management (2nd edn), McGraw-Hill, New York, U.S.A.

Lide, D.R., Baysinger, G., Berger, L.I., et al. (2004). Handbook of Chemistry and Physics, CRC press.

McCleskey, R.B., Nordstrom, D.K. and Maest, A.S. (2004). Preservation of water samples for arsenic(III/V) determinations: an evaluation of the literature and new analytical results. Appl. Geochem., 19, 995-1009.

Perrin, D.D. (1982). Ionization Constants of Inorganic Acids and Bases in Aqueous Solution, Pergamon, Oxford.

Redman, A.D., Macalady, D.L. and Ahmann, D. (2002). Natural organic matter affects arsenic speciation and sorption onto hematite. Environ. Sci. Technol, 36, 2889-2896.

Samanta, G. and Clifford, D.A. (2005). Preservation of inorganic arsenic species in groundwater. Environ. Sci. Technol., 39, 8877-8882.

Santhanam, K.S.V. and Sundaresan, N.S. (1985). Arsenic. In in A.J. Bard, R. Parsons and J. Jordan (Eds.), Standard Potential in Aqueous Solutions, Marcel Dekker Inc., New York.

Smedley, P., Nicolli, H.B., Macdonald, D.M.J., Barros, A.J. and Tullio, J.O. (2002). Hydrogeochemistry of arsenic and other inorganic constituents in groundwaters from La Pampa. Argentina. Appl. Geochem., 17, $259-284$.

Smith, A., Lingas, E. and Rahman, M. (2000). Contamination of drinking-water by arsenic in bangladesh: a public health emergency. Bullet. World Health Org., 78(9), 1093-1103.

Spliethoff, H.M., Mason, R.P. and Hemond, H.F. (1995). Interannual variability in the speciation and mobility of arsenic in a dimictic lake. Environ. Sci. Technol., 29, 2157-2161.

USEPA (2001). National primary drinking water regulations: Arsenic and clarifications to compliance and new source contaminants monitoring. Fed. Regist., 66(14), 6975-7066.

Viraraghaven, T., Subramanian, K.S. and Aruldoss, J.A. (1999). Arsenic in drinking water-problems and solutions. Wat. Sci. Tech., 40(2), 69-76.

WHO (1993). Guidelines for Drinking-water Quality (2nd edn), World Health Organization, Geneva, Switzerland. 